WANG Zhengwei, ZHAO Dongqing, ZHU Wuxiang

\title{
Are the regulations on seasoned equity offerings effective?
}

\author{
(C) Higher Education Press and Springer-Verlag 2008
}

\begin{abstract}
This paper compares the cumulative abnormal returns and operating performance of Chinese listed firms which made seasoned equity offerings or right issues at different profitability thresholds. Results show that both the average long-term and short-term cumulative abnormal returns of these firms increase significantly after the setting of thresholds. Moreover, the accounting performances of these firms are also improved to some degree. It implies that regulations on new equity raising behavior of listed firms are necessary and effective in protecting the investors and restricting listed firms' "money encirclement" behaviors.
\end{abstract}

Keywords seasoned equity offering (SEO), rights issue, regulation on SEO

摘要 在不同的配股和增发门监下, 分析进行配股和增发的公司累积超额回报率和 会计经营业绩表现。研究发现, 再融资公司股票的平均累积超额收益率与没有门槛 时相比, 无论长期还是短期都有显著提高, 会计业绩也有所改善。在我国股票市场 处于新兴和转轨阶段，为保护投资者利益，抑制“圈钱”行为，实现股票市场“发展、 规范和市场承受能力高度统一”, 以往的再融资门槛是必要和有效的。随着近年来合 格投资者力量增强, 可以考虑降低融资的财务指标门槛, 放松发行规模和时机选择

Translated and revised from Guanli shijie 管理世界 (Management World), 2006, (10): 108-113

WANG Zhengwei $(\bowtie)$

School of Economics and Management, Tsinghua University, Beijing 100084, China

E-mail: wangzhw@sem.tsinghua.edu.cn

ZHAO Dongqing

School of Economics and Management, Tsinghua University, Beijing 100084, China

E-mail: zhaodq@sem.tsinghua.edu.cn

ZHU Wuxiang

School of Economics and Management, Tsinghua University, Beijing 100084, China

E-mail: zhuwx@sem.tsinghua.edu.cn 
的限制。

关键词 增发, 配股, 再融资监管

\section{Introduction}

To confine listed firms' money encirclement behaviors, protect the interests of investors, and stabilize the stock market, China Security Regulatory Commission (CSRC) has imposed rigid regulations on listed firms' financing behaviors, including rights issue, seasoned equity offering and convertible bond issue. The standards for refinancing firms to meet for issuing new equity include thresholds for a series of financial measures such as three years' ROEs prior to the issue and the leverage ratio, along with the price and the size of the issue. Market responds positively to these new regulations.

Some researchers have questioned the effectiveness of securities market regulations. Stigler (1964) compared the market performance of industrial stocks in 1923-1928 and 1949-1955, before and after the U.S. Securities and Exchange Commission (SEC) was given control over the registration of new issues. He found that there was no significant difference between the average returns in the above two periods, and SEC's regulation only made standard deviation smaller. Stigler thus argued that SEC's regulation got rid of both the best firms and the worst firms, and therefore, investors in 1950's did not get higher returns than those in 1920's. In this sense, regulation on the securities market is not so effective. But some problems exist in Stigler's argument. One is that the significance of the changes in mean was not tested given the statistical techniques at that time. Second, the time intervals Stingler chose were biased because the Great Depression in 1929 was not included in the sample. Otherwise the pre-SEC stock returns would be much lower, which proves that regulation has effects on the market.

Empirical studies on China's listed firms have found that the profitability threshold ("threshold" hereafter) of SEO induced earnings management (e.g., Chen et al., 2000; Yan et al., 2001; Song, 2003), or even fraud behaviors (e.g., Ping et al., 2003; Liu and Liu, 2003). These empirical papers focused on the negative effects of the SEO threshold, leaving the question of whether SEO threshold itself is effective unanswered. Wu et al. (2005) studied the rationality of setting SEO threshold by examining the long-term market performance and operating performance of the SEO firms. They found that firms with "good performance" which meet the SEO threshold tend to perform poorly after the issue of new equity, as compared with firms which do not issue new equity. Though CSRC has adjusted SEO thresholds over time, there are no significant differences in the long-term performance measured by cumulative abnormal 
returns for the reissuing firm with different thresholds. Therefore, SEO threshold does not conduct the function of decreasing the information asymmetry and protecting investors. They hence suggested that regulators need to reconsider the role of the SEO threshold and cancel the threshold gradually and turn to rely on investment bank instead as reliable judger of the quality of listed firms. The test method used in Wu's article, however, might be problematic. First, the comparison between the reissuing firms and non-reissuing firms (including the market portfolio and the industry-size comparable firms) can not prove whether the threshold is effective or not. A better way to test it is to compare "with threshold" with "without threshold", or compare "low threshold" with "high threshold". Second, Wu, et al. defined the cumulative abnormal returns in their paper as the ROE difference between the reissuing firms and the market portfolio or comparable firms. In an economic sense, this definition was not explicit enough. Finally, the results in Table 7 and 8 in this paper show that reissuing firms with threshold outperform the reissuing firms without threshold, and demonstrate the threshold is effective in selecting high quality firms. Wang and Zhu (2006) built a model showing that in an inefficient stock market, firms can seize the benefit of new public investors through SEO. Regulation of securities market is necessary to protect the public investors.

In this paper, we investigate whether the SEO threshold is effective by comparing the performances of reissuing firms at different SEO thresholds. Our paper follows Wu's approach, but draws a different conclusion.

This paper proceeds as follows: Section 1 is an introduction. In Section 2, we present our data and procedures. Section 3 shows the empirical results. Conclusions and implications are contained in the last section.

\section{Data and methods}

\subsection{Data}

Samples were chosen from A-share firms listed in Shanghai and Shenzhen Security Exchange from 1994 to 2003. As a routine, financial firms were excluded. All the equity issues were included in the sample except the initial public offerings. Since CSRC sets different thresholds for seasoned equity offerings and rights offering, we collected SEO sample and rights offering sample respectively. Each sample is divided into several sub-samples in accordance with threshold changes over time. Moreover, considering the multiple issues during the sampling period, the most recent issue will be put into the corresponding sub-sample. Table 1 provides different thresholds for rights offering and related samples. Table 2 describes different thresholds for SEO and 
related samples. All the data was obtained from the Tsinghua Financial Database.

Table 1 Threshold for right offerings and sample classification

\begin{tabular}{|c|c|c|c|}
\hline Time interval & Threshold & $\begin{array}{l}\text { No. of } \\
\text { issues }\end{array}$ & Sample \\
\hline 1994.1.1-1994.12.19 & No specific requirement for $\mathrm{ROE}$ & 64 & Sample 1 \\
\hline 1994.12.20-1996.1.24 & $\begin{array}{l}\text { Average ROE for the most recent three } \\
\text { years shall be higher than } 10 \% \text {. ROE } \\
\text { of energy, raw materials or } \\
\text { infrastructures firms could be slightly } \\
\text { lower than } 10 \%\end{array}$ & 76 & Sample 2 \\
\hline 1996.1.25-1999.3.26 & $\begin{array}{l}\text { ROE for each of the most recent three } \\
\text { years shall be higher than } 10 \% \text {, ROE } \\
\text { of energy, raw materials or } \\
\text { infrastructures firms could be slightly } \\
\text { lower than } 10 \% \text {, but no lower than } 9 \%\end{array}$ & 347 & Sample 3 \\
\hline 1999.3.27-2001.3.14 & $\begin{array}{l}\text { Average ROE for the most recent three } \\
\text { years shall be higher than } 10 \% \text { and the } \\
\text { ROE of any of these three years should } \\
\text { be no lower than } 6 \% \text {. ROE of } \\
\text { agriculture, energy, raw materials, } \\
\text { infrastructures or high-tech firms could } \\
\text { be lower than } 9 \%\end{array}$ & 330 & Sample 4 \\
\hline 2001.3.15-2003.12.31 & $\begin{array}{l}\text { Average ROE for the most recent three } \\
\text { years shall be higher than } 6 \%\end{array}$ & 83 & Sample 5 \\
\hline
\end{tabular}

Table 2 Thresholds for SEO and sample classification

\begin{tabular}{cccc}
\hline Time interval & \multicolumn{1}{c}{ Threshold } & $\begin{array}{c}\text { No. of } \\
\text { issues }\end{array}$ & Sample \\
\hline 1998.1.1-2000.4.29 & $\begin{array}{l}\text { No specific requirement for ROE } \\
\text { Money-making for the most recent } \\
\text { three years; ROE for the current } \\
\text { year shall be no lower than bank's } \\
\text { deposit interest rate of the } \\
\text { corresponding period } \\
\text { Average ROE for the most recent } \\
\text { three year shall be higher than 6\% } \\
\text { Average ROE for the most recent } \\
\text { three year shall be higher than } \\
\text { 10\% and ROE in the last reporting } \\
\text { year shall be no lower than 10\% }\end{array}$ & $\begin{array}{l}\text { Sample 6 } \\
\text { Sample 7 }\end{array}$ & Sample 8 \\
& & Sample 9 \\
\hline
\end{tabular}

\subsection{Methods}

To investigate the effectiveness of the above thresholds, we need to empirically measure the market performance and operating performance of SEO firms and rights issue firms. Different from most of extant studies, we compared reissuing firms with threshold with those reissuing firms without threshold aiming to 
discover whether the former outperform the latter during the post-issue period.

\subsubsection{Market performance measurement}

Cumulative Abnormal Return (CAR) was adopted to measure a firm's market performance. The formula ${ }^{1}$ used is as follows:

$$
C A R_{i d}=\sum\left(R_{i d}-R_{m d}\right)
$$

Where $R_{i d}$ is the post-issue daily stock returns for an individual firm, and $R_{m d}$ the corresponding daily returns of the market portfolio.

\subsubsection{Operating performance measurement}

$R O A$ and $R O E$ are widely used as indexes of operating performance. $R O A$ is defined as net income divided by total assets and $R O E$ is defined as net income divided by total shareholders' equity. To eliminate the influence of the factors which change over time, such as macro-economy, industry policy, etc., we used abnormal $R O A$ and abnormal $R O E$ instead to measure operating performance. Accordingly, their definitions ${ }^{2}$ are as follows:

$$
\begin{aligned}
& \text { Abnormal } R O A=\text { individual firm's } R O A \text {-average industry } R O A \\
& \text { Abnormal } R O E=\text { individual firm's } R O E \text {-average industry } R O E
\end{aligned}
$$

Where the average industry $R O A$ is the total net income of all listed firms in one industry divided by the total assets of all listed firms in that industry, and the average industry $R O E$ is the total net income of all listed firms in one industry divided by the total shareholders' equity.

\section{Empirical results}

\subsection{Post-issue market performance}

\subsubsection{Rights issues}

Fig. 1 and Table 3 present the average $C A R$ over 300 trading days for samples

\footnotetext{
${ }^{1}$ Relevant literature has shown that using market returns to calculate abnormal returns is better than using CAPM. We hence adopted stock returns minus market returns to calculate abnormal returns in this research.

${ }^{2} \mathrm{Wu}$ et al. (2005) defined the abnormal $R O A$ as the reissuing firm's ROE minus the average $R O E$ of the market portfolio, a definition slightly different from ours. However, the results will still support our conclusion even if we had used their definition.
} 
1-5. Results show that Sample 2 differs significantly from Sample 1, regardless of in long term or short term, which implies that market responds positively to the setting of rights issue threshold. Moreover, samples 3-5 also differ significantly from Sample 1. These results strongly support that regulations on the rights issue by setting threshold are effective and are hence welcomed by the market.

The results in Fig. 1 and Table 3 also show that market responds each time when CSRC changes the threshold. Sample 2 contains a group of firms when CSRC first set the threshold, and it outperforms the other samples. For firms in Sample 3, the threshold has been raised to a higher level. The 30-day CAR is significantly higher than that of in Sample 2, while the 300-day CAR is significantly lower. As compared with Sample 3, the threshold decreases in Sample 4, whose short-term average CAR (30-day and 100-day) is significantly higher than that of in Sample 3, while the long-term average CAR 200-day and 300-day) does not differ significantly from Sample 3. The threshold for Sample 5 is also lower than that of Sample 4. But since CSRC changes the threshold too frequently, stock market does not respond so actively to this new change. No matter in short-term or long-term, the average CARs for Sample 5 are significantly lower than that of in Sample 4. Fig. 1 shows that the market responded negatively to Sample 2 at the beginning, for the CAR in Sample 2 goes up very quickly over time. As for Sample 3 to 5, their CARs are positive and changes mildly over time.

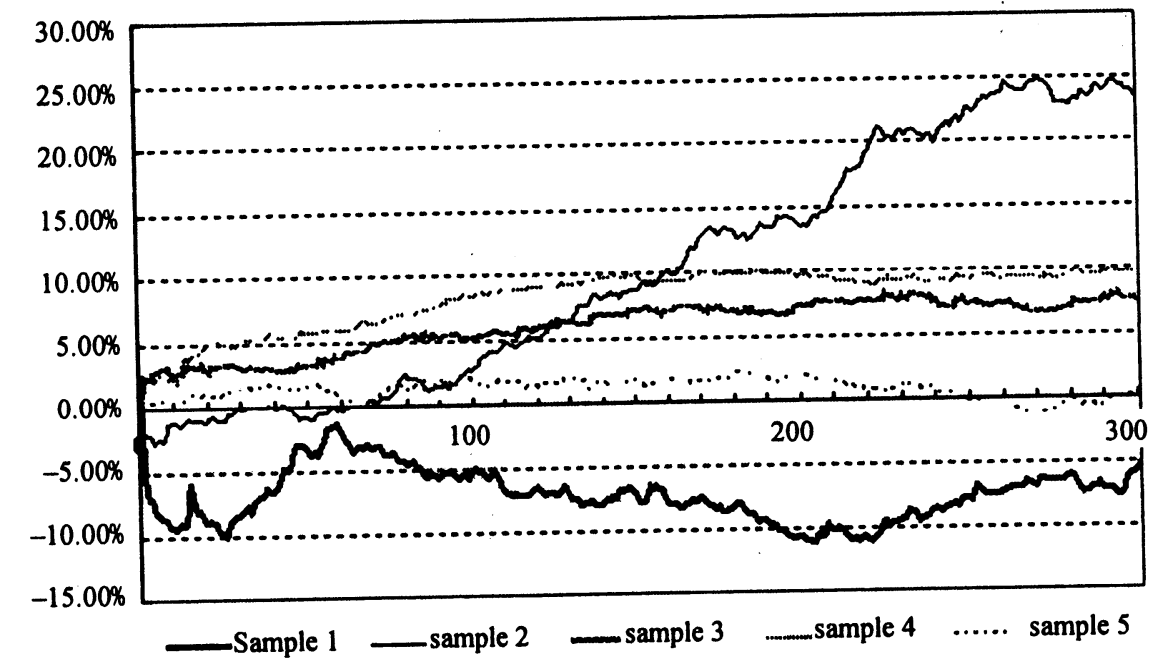

Fig. 1 Average CARs of samples 1-5 during 300 trading days 


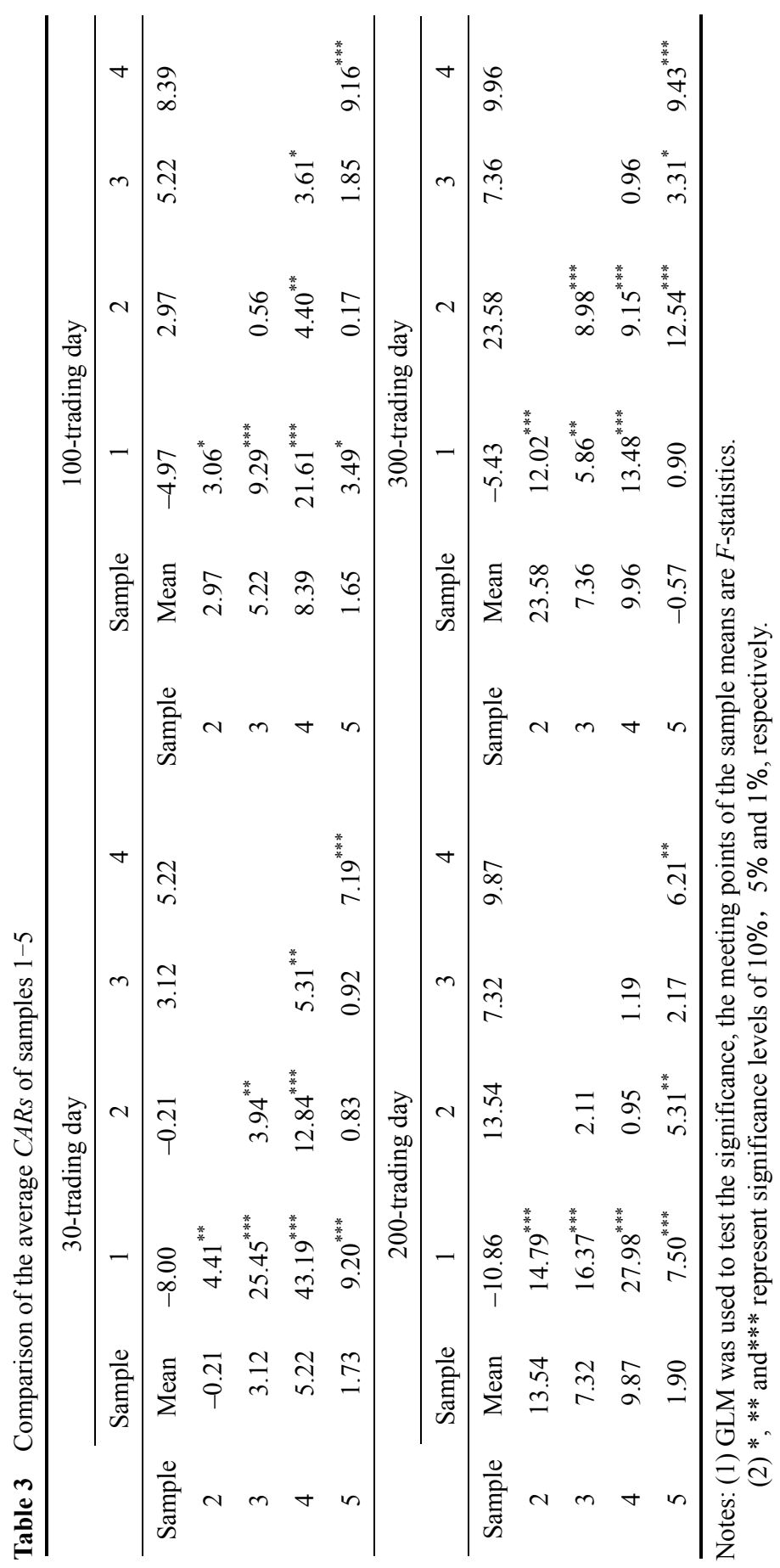


The results show that the threshold for rights offering plays an important role in protecting public investors. The market's reaction to the rights offering varies with time: When the threshold has been presented for a long time, the sensitivity of the market to changes in threshold tends to decline. Since China's stock market is still far from being mature and efficient, setting threshold can effectively protect public investors by restraining listed firms from issuing equity arbitrarily.

\subsubsection{SEO}

Fig. 2 and Table 4 describe changes in average CAR in 300 trading days for SEO firms with different thresholds. Similar to the rights offering samples, when the threshold does not exist, the market responds negatively to SEO, as shown in the average CAR for Sample 6. The 300-trading day average CAR is negative for Sample 6. Though still negative, the average CARs for samples 7-9 are all higher than that of Sample 6, showing that after introducing SEO threshold, the average quality of the issuing firms has been improved to a certain degree. It also demonstrates that the SEO threshold plays an important role in protecting the public investors. As for different thresholds, no matter if in short-term or long-term, market performance does not vary significantly.

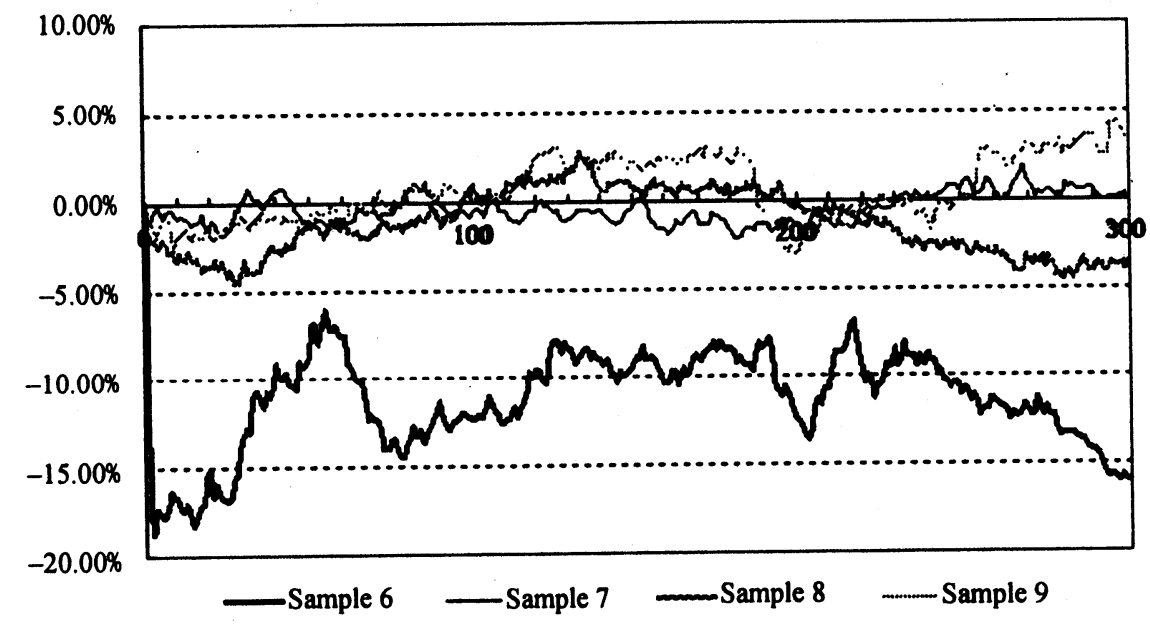

Fig. 2 Average $C A R s$ of samples $6^{-9}$ during a post-issue 300 successive trading days 
Table 4 Comparison of the average CARs of samples 6-9

\begin{tabular}{|c|c|c|c|c|c|c|c|c|c|}
\hline & \multicolumn{3}{|c|}{30 -trading day } & & \multicolumn{5}{|c|}{ 100-trading day } \\
\hline & Sample & 6 & 7 & 8 & & Sample & 6 & 7 & 8 \\
\hline Sample & Mean & -12.83 & 0.28 & -3.28 & Sample & Mean & -12.41 & -0.47 & 0.80 \\
\hline 7 & 0.28 & $7.94^{* * *}$ & & & 7 & -0.47 & $4.92^{* *}$ & & \\
\hline 8 & -3.28 & $4.39^{* *}$ & 1.18 & & 8 & 0.80 & $6.06^{* *}$ & 0.11 & \\
\hline 9 & -3.50 & $3.50^{*}$ & 1.09 & 0.01 & 9 & -1.11 & 2.30 & 0.01 & 0.12 \\
\hline \multicolumn{5}{|c|}{ 200-trading day } & \multicolumn{5}{|c|}{ 300-trading day } \\
\hline & Sample & 6 & 7 & 8 & & Sample & 6 & 7 & 8 \\
\hline Sample & Mean & -12.45 & -1.38 & -0.22 & Sample & Mean & -15.93 & -0.13 & -3.77 \\
\hline 7 & -1.38 & $3.46^{*}$ & & & 7 & -0.13 & $4.04^{*}$ & & \\
\hline 8 & -0.22 & $4.62^{* *}$ & 0.07 & & 8 & -3.77 & $3.01^{*}$ & 0.27 & \\
\hline 9 & -1.62 & 1.34 & 0.01 & 0.04 & 9 & 2.07 & 2.51 & 0.05 & 0.40 \\
\hline
\end{tabular}

\subsection{Post-issue operating performance}

\subsubsection{Rights issue}

Fig. 3 presents the average abnormal ROAs of samples $1-5$, where " 0 " represents the financial report date ${ }^{3}$ six months before the issue. "1", "2", "3" and " 4 " represent six months, one year, one and a half years, and two years after the issue respectively. The underperformance of all samples after their rights issues gives certain evidence that a "face-changing" phenomenon does exist among China's listed firms. Although all five samples perform poorer after the issue, samples 2-5 outperform sample 1 in every period. Therefore, the threshold of the rights issue is obviously effective in filtering out good-quality firms from bad ones.

The comparison of samples 1-5 is shown in Table 5. The difference between Sample 2 and Sample 1 is significant only at date 0, which can not be used to verify the effectiveness of rights issue thresholds. But as the threshold changes, samples 3-5 differs from each other significantly at date 0,1 and 2, Sample 4 differs from Sample 1 significantly at date 3, and Sample 3 and 5 differ from Sample 1 significantly at date 4 , which demonstrate the sifting function of rights issue thresholds. Additionally, the significant difference between samples 3-5 and Sample 2 shows that changes in threshold do make sense.

\footnotetext{
${ }^{3}$ The financial report date refers to the semi-annual report date or annual report date.
} 


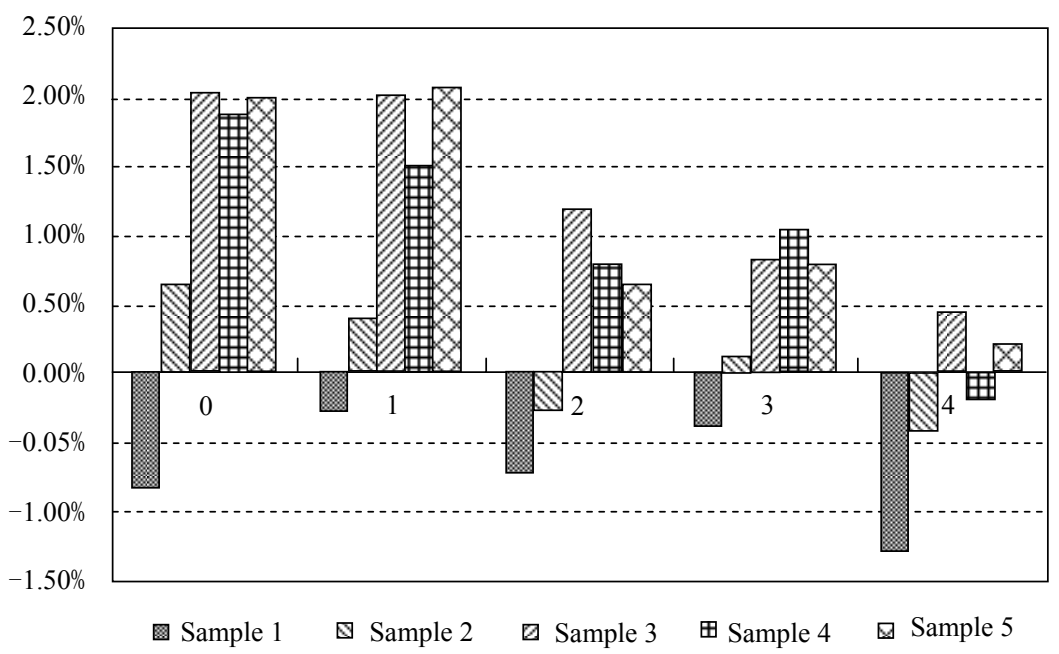

Fig. 3 Average abnormal ROAs of samples 1-5

Similar to Fig. 3, Fig. 4 exhibits the average abnormal ROEs of samples 1-5, which shows that the very existence of thresholds helps improve the average performance of the issuing firms. Table 6 is a comparison of the average abnormal ROEs of samples $1-5$.

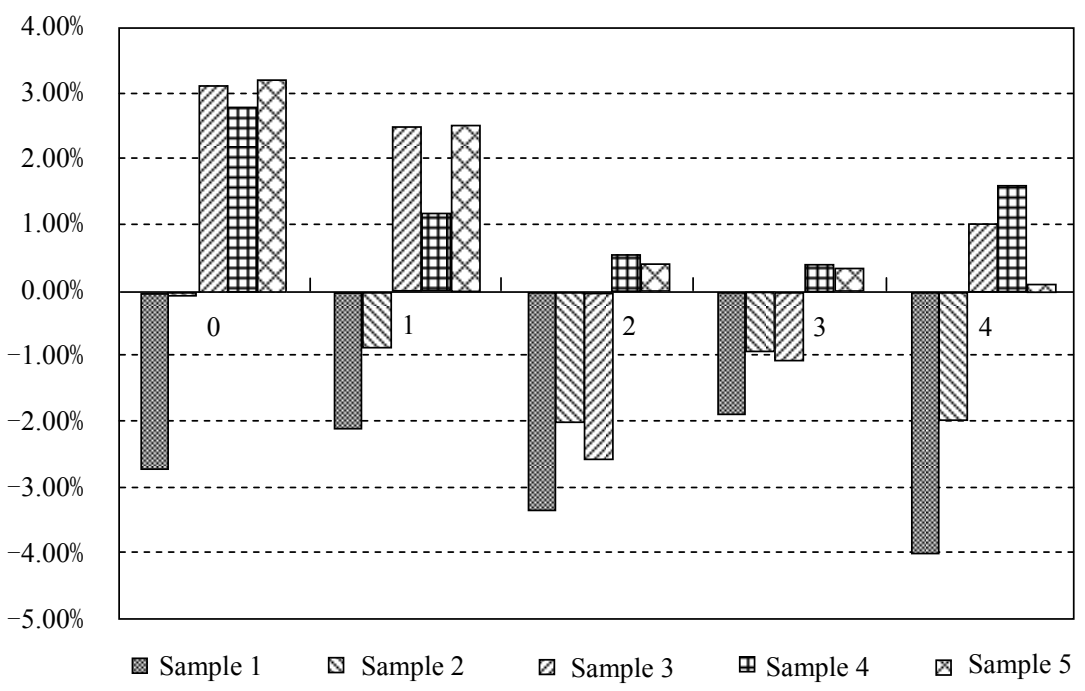

Fig. 4 Average abnormal ROEs of samples 1-5 


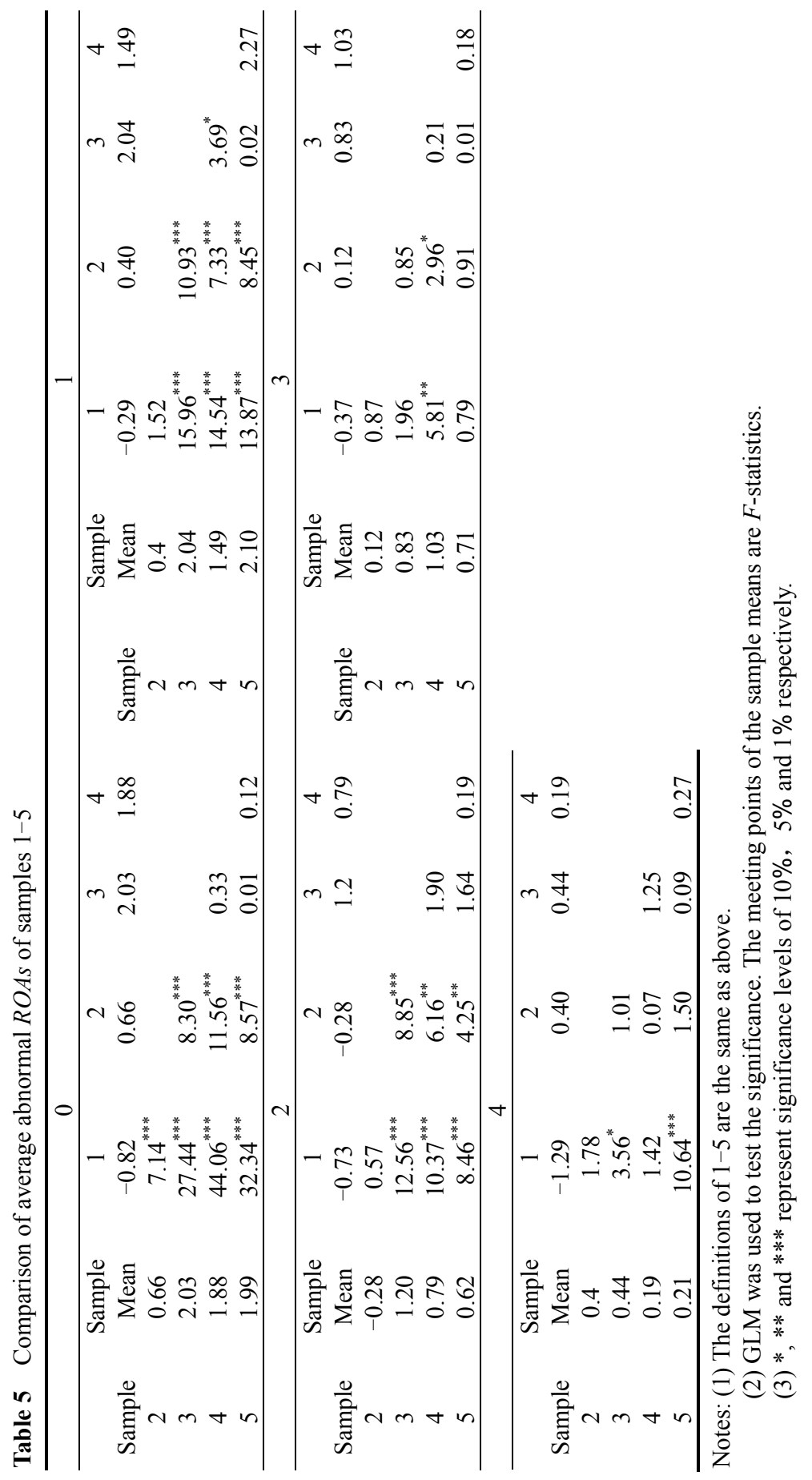




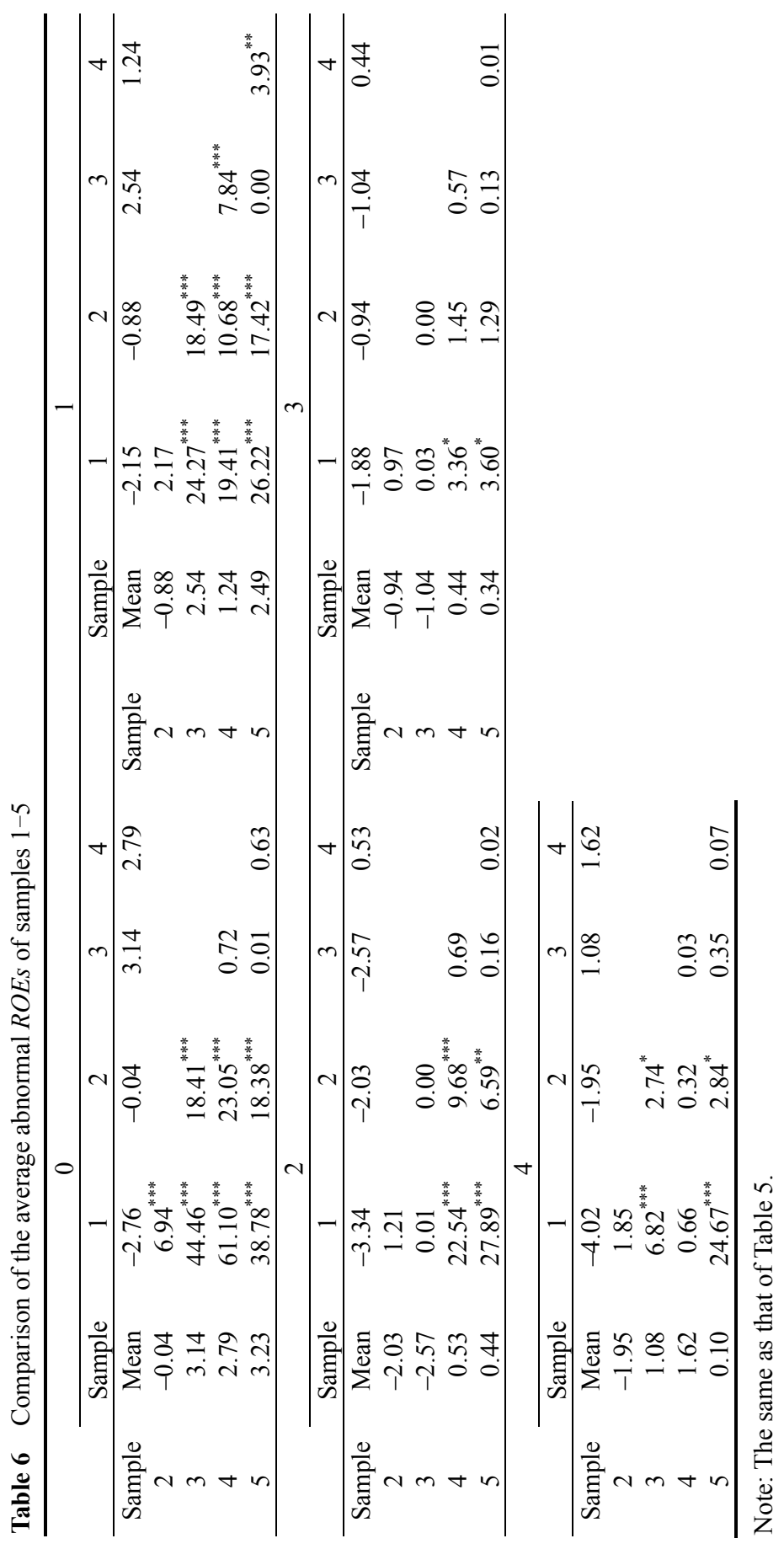




\subsubsection{SEO}

Fig. 5 and Fig. 6 present respectively the average abnormal ROAs and ROEs of samples 6-9. A similar conclusion to the case of samples 1-5 can be drawn from them. Measured by average abnormal $R O A$ and $R O E$, the operating performance has been declining since SEO is conducted, even in the case without SEO threshold. But samples 7-9 outperform Sample 6 at each date, showing that SEO threshold is still effective in sifting good firms.

Table 7 and 8 compare the average abnormal ROAs and ROEs of samples 6-9 respectively. Table 7 illustrates that samples 7-9 differ from sample 6 significantly, but the significance turns weaker as the time interval becomes longer. The difference between samples 7,8 and 9 is not significant as a whole. Table 8 tells that there are significant differences among samples 7, 8 and 6 , but the difference disappears in one year. There are no significant differences among samples 7, 8 and 9. The results show that the issuing firms do improve significantly their operating performances when SEO threshold exists. But as the threshold changes, there is no significant change in operating performance for the issuing firms.

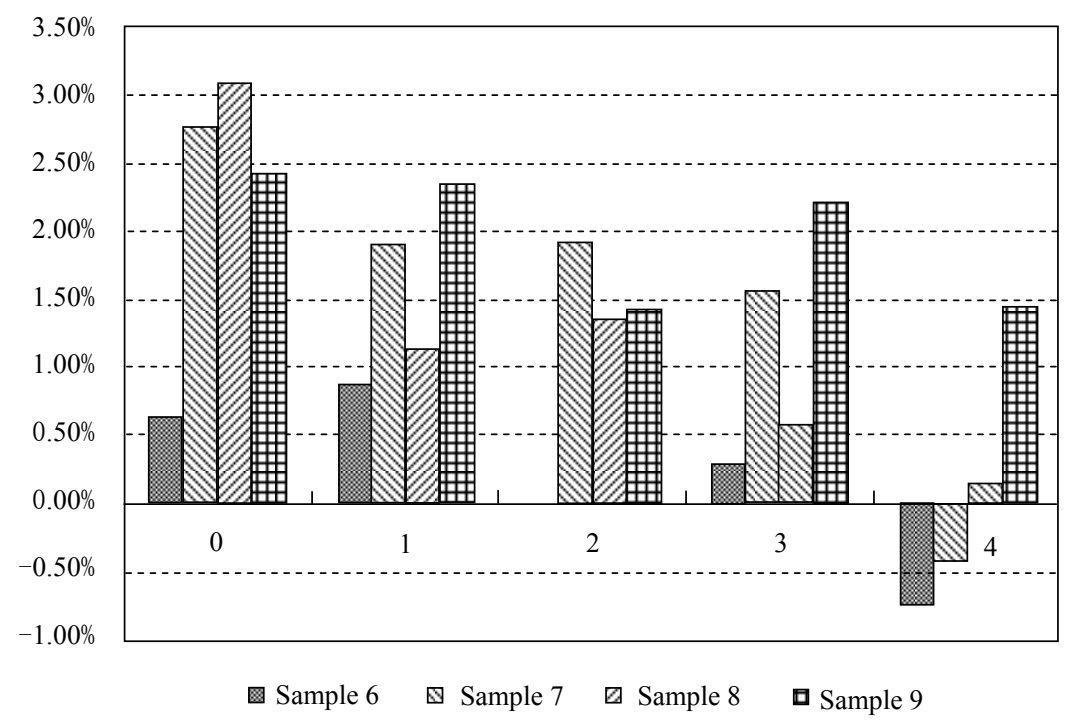

Fig. 5 Average abnormal ROAs of samples 6-9 
Table 7 Comparison of average abnormal ROAs of samples 6-9

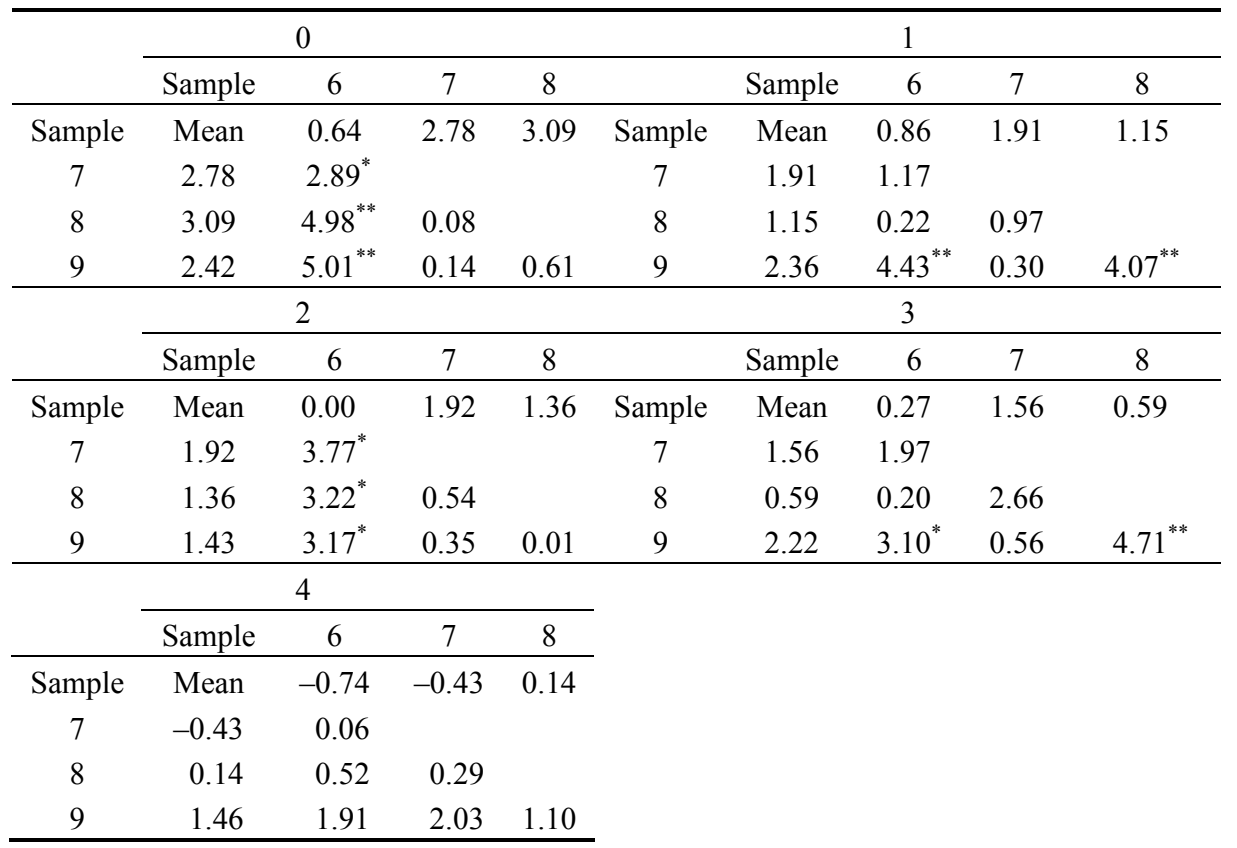

Note: The same as that of Table 5.

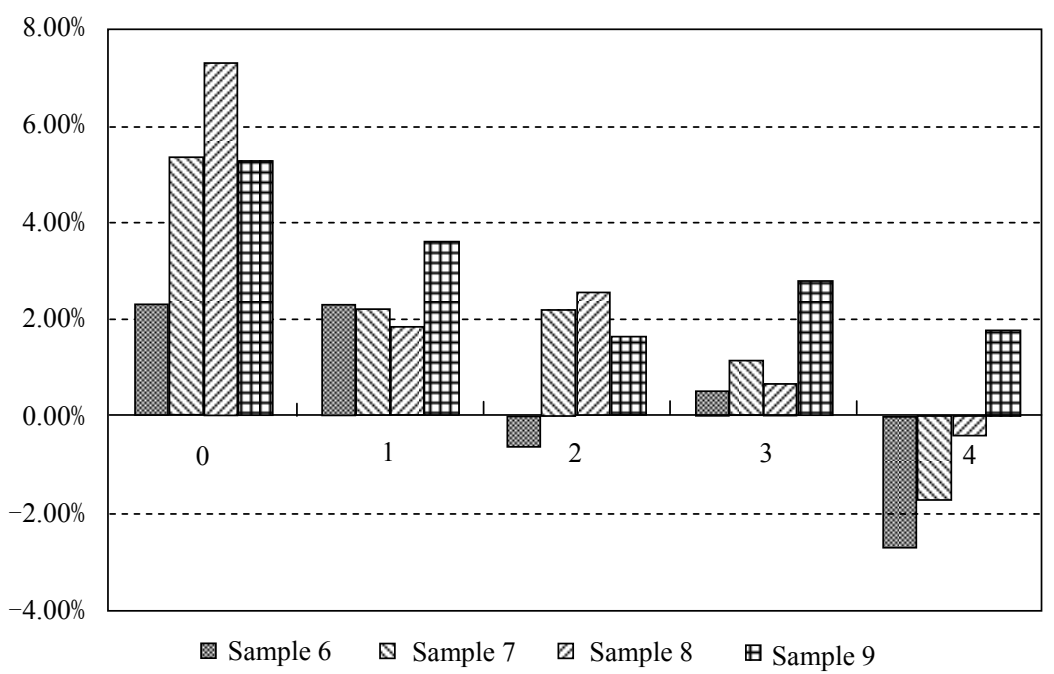

Fig. 6 Average abnormal ROEs of samples 6-9 
Table 8 Comparison of average abnormal ROEs of samples 6-9

\begin{tabular}{|c|c|c|c|c|c|c|c|c|c|}
\hline \multicolumn{5}{|c|}{0} & \multicolumn{5}{|c|}{1} \\
\hline & Sample & 6 & 7 & 8 & & Sample & 6 & 7 & 8 \\
\hline Sample & Mean & 2.32 & 5.33 & 7.31 & Sample & Mean & 2.37 & 2.23 & 1.84 \\
\hline 7 & 5.33 & 1.78 & & & 7 & 2.23 & 0.01 & & \\
\hline 8 & 7.31 & $4.69^{* *}$ & 0.94 & & 8 & 1.84 & 0.28 & 0.11 & \\
\hline \multirow[t]{3}{*}{9} & 5.24 & 2.39 & 0.00 & 1.21 & 9 & 3.67 & 0.84 & 1.01 & 2.45 \\
\hline & \multicolumn{4}{|c|}{2} & \multicolumn{5}{|c|}{3} \\
\hline & Sample & 6 & 7 & 8 & & Sample & 6 & 7 & 8 \\
\hline Sample & Mean & -0.64 & 2.22 & 2.57 & Sample & Mean & 0.50 & 1.16 & 0.66 \\
\hline 7 & 2.22 & $2.81 *$ & & & 7 & 1.16 & 0.25 & & \\
\hline 8 & 2.57 & $3.61 *$ & 0.07 & & 8 & 0.66 & 0.02 & 0.41 & \\
\hline \multirow[t]{3}{*}{9} & 1.65 & 1.97 & 0.19 & 0.49 & 9 & 2.78 & 1.41 & 1.37 & 2.67 \\
\hline & \multicolumn{4}{|c|}{4} & & & & & \\
\hline & Sample & 6 & 7 & 8 & & & & & \\
\hline Sample & Mean & -2.69 & -1.77 & -0.40 & & & & & \\
\hline 7 & -1.77 & 0.07 & & & & & & & \\
\hline 8 & -0.40 & 0.68 & 0.48 & & & & & & \\
\hline 9 & 1.75 & 1.78 & 2.15 & 1.45 & & & & & \\
\hline
\end{tabular}

Note: The same as that of table 5.

\section{Conclusions}

The aim of this paper is to find out whether SEO or rights issue thresholds are effective or not. We begin by measuring the market performance of issuing firms and find that both SEO firms and rights offering firms perform better significantly in both short-term and long-term after the threshold was set. Results also show that for both SEO firms and rights issuing firms, a kind of "face-changing" phenomenon does exist in terms of operating performance. Two possible explanations are: First, newly issuing firms are prone to perform poorly even when there is no threshold; Second, empirical evidence shows that the operating performances improve to a certain extent for issuing firms once the threshold is set.

Like in most transition economies, China's stock market is far from being mature. The Chinese government thus needs to set stricter rules to regulate market behaviors. But so far the enforcement of these rules has not been satisfactory. On one hand, manipulations prevail in the market and some intermediary institution break rules frequently, resulted from a lack of effective laws to protect investors. Consequently, investors are tempted to speculate in short-term trading. On the other hand, due to reasons such as bad corporate governance, low cost of breaking regulating rules and share splits, etc, Chinese 
listed firms of different quality all have strong incentives to issue new equity, which is used as an effective means of "money encirclement". Stein (1996) found that shareholders create values for themselves through external financing by taking advantage of the market opportunities. Investors in A-share market are constantly calling for raising the threshold of security issues, strictly regulating the securities issuing and restricting listed companies' "money encirclement" behaviors. Statistics show that each time when CSRC raises the threshold, market responds positively, while when the threshold is lowered, market goes down with it. Sometimes, this kind of downturn may even prolong.

The refinancing thresholds set by CSRC include the financial ratios reflecting a firm's performance history, the total amount of the issue, and the time of issuing. In doing so, CSRC aims to protect the interests of the floating stock shareholders and to stabilize the market. Extant research has shown that these thresholds can not guarantee that firms with excellent performances in the past will perform equally well in the future. Sometimes, these thresholds may even have negatively effects on listed firms. For example, some firms may not be able to finance for good projects because they failed to pass the refinancing threshold. Some firms may be compelled to refinance for bad projects through earnings manipulation. But in this paper, we still find evidence showing that the average qualities of reissuing firms have been improved to a certain degree since the threshold was set. Because the thresholds can restrict the "money encirclement" behaviors of some underperforming firms, protect the interests of investors and stabilize the market, they can thus be used as effective tools by the securities regulatory authorities.

Past experience drawn from foreign countries has illustrated that rigid regulations introduced in the early stage of securities market development, especially after a severe recession, can effectively protect the investors from fraud. For example, after the South Sea Bubble in England in 1711, British government passed the Anti-Bubble Act that required firms to get the approval of the Parliament when they conducted IPO. French government set strict regulations on new securities issuing for over 160 years after the Mississippi Bubble had happened in 1718. China's stock market has developed very quickly in recent years. Statistics show that the number of listed firms reached 1377 at the end of 2004 from a mere 10 in 1990 and there were over 72.1 million investors at the end of 2004, ${ }^{4}$ which exceeded Russia, Poland and other East-European transition countries (Pistor and $\mathrm{Xu}, 2005$ ). Partly due to the Chinese government's timely intervention and regulation, stock market fluctuation has never happened in China as serious and frequent as in other

\footnotetext{
${ }^{4}$ Data of the number of listed firms and A-share issue size were obtained from CSRC's statistics in Jan. 2005.
} 
emerging markets.

The paper provides strong evidence to support the effectiveness of the refinancing thresholds. Recently, more qualified institutional investors have participated in A-share market, which improves the investor structure of Chinese stock markets considerably. In addition, more rules have been set up to regulate market participants, and China's share split reforms will be accomplished, too. Therefore, we suggest that CSRC reduce or even cancel the restrictions on the issue size and time gradually, and in the end give investor the rights to decide for themselves the quality of reissuing firms.

Acknowledgements This work is supported by the National Natural Science Foundation of China (No: 70272010).

\section{References}

Chen Xiaoyue, Xiao Xing, Guo Xiaoyan(2000). The right of rationed share acquisition and profit manipulation by listed Company. Economic Research Journal, (1): 30-36 (in Chinese)

Liu Bin, Liu Xing(2003). Study on the fraud of the listed companies by the game theory. Commercial Research, 3: 79-81 (in Chinese)

Ping Xinqiao, Li Ziran(2003). Qualification for refinancing and noisy disclosure of information. Economic Research Journal, 2: 55-63 (in Chinese)

Pistor K, Xu Chenggang(2005). Governing stock markets in transition economies: Lessons from China. American Law and Economics Review, 17: 184-210

Song Fenghua(2003). The Empirical Analysis on Earnings Managements of the Listed Firms in China (Dissertation for Master Degree). Tsinghua University

Stein J C(1996). Rational capital budgeting in an irrational world. The Journal of Business, (4): $429-455$

Stigler G J(1964). Public regulation of the securities markets. The Journal of Business, (2): $117-142$

Wang Zhengwei, Zhu Wuxiang(2006). The protection of investors and the regulation on security issue. Nankai Economic Studies, (1): 79-87 (in Chinese)

$\mathrm{Wu}$ Wenfeng et al.(2005). The rationality of founding "thresholds" to reissuing viewed from the long-term achievements. Management World, (5): 127-134 (in Chinese)

Yan Dawu, Geng Jianxin, Liu Wenpeng(2001). The positive researches on behavior of rights issue financing of listed companies in China. Accounting Research, (9): 21-27 (in Chinese) 